\title{
Fabricar a inovação na Educação Superior: estratégias para a Educação a Distância em Portugal
}

\author{
Fabricating innovation in Higher Education: Strategies for Distance Education \\ in Portugal \\ Fabricar la innovación en la Educación Superior: estrategias para la Educación \\ a Distancia en Portugal \\ DOMINGOS CAEIRO \\ JOSÉ ANTÓNIO MOREIRA
}

\begin{abstract}
Resumo: A aprendizagem aberta e em rede emerge como um dos grandes desafios educativos do presente século. No entanto, este desafio exige pensamento e estratégias orientados não só para a sustentabilidade das instituições que a promovem e para a qualidade da sua oferta educativa, como também para a definição de políticas que, sensíveis às profundas assimetrias sociais e educativas existentes, integrem a Educação a Distância $(\mathrm{EaD})$ no quadro de uma pedagogia pública, de uma democracia participativa. Assim, o presente artigo contém algumas ideias basilares para a promoção de um debate sobre a EaD na Educação Superior, analisando possíveis estratégias e medidas que urge definir para este subsistema educativo.
\end{abstract}

Palavras-chave: Educação a Distância; Ensino Superior; inovação; sociedade digital.

\begin{abstract}
Open and networked learning emerges as one of the great educational challenges of the present century. However, this challenge demands some thought and strategies geared not only to the sustainability of the institutions that promote it and to the quality of its educational offer, but also to the definition of policies that, sensitive to deep social and educational asymmetries, integrate Distance Learning (DL) within the framework of a public pedagogy and a participatory democracy. Therefore, the present article contains some important ideas for the promotion of a debate on DL in Higher Education, analyzing possible strategies and concrete measures that need to be defined for this educational subsystem.
\end{abstract}

Keyword: distance learning; higher education; innovation; digital society.

Resumen: El aprendizaje abierto y en red emerge como uno de los grandes desafíos educativos del presente siglo. Sin embargo, este desafío exige pensamiento y estrategias orientadas no solo a la sostenibilidad de las instituciones que lo promueven y a la calidad de su oferta educativa, sino también a la definición de políticas que, sensibles a las profundas asimetrías sociales y educativas existentes, 
integran la Educación a distancia $(\mathrm{EaD})$ en el marco de una pedagogía pública, de una democracia participativa. Así, el presente artículo contiene algunas ideas fundamentales para la promoción de un debate sobre la EaD en la Educación Superior, analizando posibles estrategias y medidas que deben definirse para este subsistema educativo.

Palabras clave: Educácion a Distancia; Educácion Superior; innovación; sociedad digital.

\section{INTRODUÇÃO}

A sociedade digital e as tecnologias que produz alteraram os modos como se interage, trabalha ou aprende ou, se preferirmos, as capacidades e competências sociais, culturais, educacionais necessárias para o exercício de uma cidadania plena (CAEIRO; MOREIRA, 2017). Os jovens e os cidadãos em geral, através dos seus processos de qualificação e formação (formação inicial, requalificações, e outros processos educativos e formativos integrados numa lógica de Aprendizagem ao Longo da Vida, etc.), são parte fundamental dessas mudanças e as Instituições de Ensino Superior (IES) têm de encontrar respostas para os novos públicos que as procuram.

No âmbito da apresentação das conclusões preliminares do relatório da Organização de Cooperação e de Desenvolvimento Económico (OCDE) sobre o Sistema de Ensino Superior, Ciência e Inovação, a pedido do Ministério da Ciência, Tecnologia e Ensino Superior em Portugal, tornou-se claro que é urgente que o poder político se empenhe na definição e implementação de estratégias que conduzam as universidades portuguesas a níveis mais altos da universalidade da sua missão: formar cidadãos, produzir conhecimento e fabricar Ciência.

A educação dos cidadãos para uma cultura participativa apela a novas lógicas sensíveis não só à diluição de fronteiras individuais, institucionais e nacionais, como também à articulação de políticas orientadas para os ideais de democracia, coesão social e igualdade de acesso à Educação. Deste modo, pensar a Educação para os direitos humanos, para uma cidadania plena e para a inclusão social, significa, necessariamente, uma reflexão sobre os papéis do Ensino Superior neste novo paradigma.

Envolvidas em processos de mudança, frequentemente justificados por políticas difusas e medidas instrumentais avulsas, as instituições do Ensino Superior (IES) em Portugal, ainda muito marcadas por uma cultura educativa tradicional e elitista, têm-se confrontado com a necessidade de reinventarem o seu papel científico, social e educativo. Este novo paradigma emergente vinculase, praticamente, a todos os âmbitos de organização económica, social, cultural e política e resulta, entre outros, do processo de globalização da economia e da 
comunicação, da evolução de uma consciência de mundialização, de uma cultura em rede, da internacionalização do saber e da ciência e da estreita relação entre a participação digital e as novas práticas de cidadania.

Nesse sentido, a Educação a Distância (EaD) apresenta-se como uma possibilidade que vem ao encontro desse novo paradigma, e como uma alternativa para que as IES se aproximem dos seus públicos (estudantes) e da sociedade (cidadãos), e transformando este desafio num diferencial competitivo. Com efeito, a partir praticamente dos inícios do séc. XXI, a emergência de novas culturas e ferramentas digitais deram à $\mathrm{EaD}$ uma outra visibilidade e exigência social. As culturas em rede, a interatividade e colaboração, os ambientes hibridos, multimodais e ubíquos, as comunidades digitais em rede ampliaram o espetro de possibilidades e de ação da EaD, associando-a a uma dimensão de intervenção claramente digital.

Uma educação digital híbrida compreendida quanto à natureza dos seus espaços, quanto à presença, quanto às tecnologias e quanto à cultura; uma educação digital multimodal e remixada, com expressão no eletronic learning (e-learning), pervasive learning (p-learning), immersive learning (i-learning), game based learning (GBL), ubiquos learning (u-learning) on mobile learning (m-learning); e uma educação digital ubíqua relacionada com processos de aprendizagem que podem ocorrer com o uso de dispositivos móveis, conectados a redes de comunicação sem fios, sensores e mecanismos de geolocalização, capazes de colaborar para integrar os estudantes a contextos de aprendizagem, permitindo formar redes virtuais entre pessoas, objetos e situações (SCHLEMMER, 2016).

São nestes ambientes, híbridos, multimodais e ubíquos, que os jovens e os cidadãos, em movimento e hiperconectados com dispositivos móveis, constroem conhecimento e aprendem. A hiperconexão é uma realidade, e é por meio destas conexões permanentes que o mundo se organiza, se constroem as subjetividades e se aprende (PORTO; MOREIRA, 2017). Mas tão, ou mais importante, que esta conectividade e estado permanente em rede, é o fator de convergência e a imersividade inerentes às novas estruturas narrativas transmidiáticas em formatos multimodais que nos permitem esta ubiquidade, conexão e nomadismo. Convergência entendida como a circulação -linear ou não- de conteúdos, em diferentes plataformas, sistemas e dispositivos, definida pelo fluxo de informação por meio destes canais de comunicação. Sendo que para Jenkins (2009) a convergência não se refere a uma estrutura tecnológica, refere-se sim às conexões profundas e complexas, criadas num nível cognitivo de perceção dos indivíduos, considerando o seu estado ubíquo de acesso e navegação dentro de diferentes ambientes digitais. 
A aprendizagem aberta e em rede nestes ambientes emerge, assim, como um dos grandes desafios educativos do presente século. No entanto, este desafio exige pensamento e estratégias orientados não só para a sustentabilidade das instituições que a promovem e para a qualidade da sua oferta educativa, como também para a definição de políticas que, sensíveis às profundas assimetrias sociais e educativas existentes na sociedade digital, integrem a EaD no quadro de uma pedagogia pública, de uma democracia participativa.

A EaD em Portugal tem sido cenário de grandes contradições. Pese embora os relatórios e outros documentos produzidos por investigadores, consultores e outros especialistas sobre as potencialidades da $\mathrm{EaD}$ e da Universidade Pública Portuguesa de EaD na expansão do Ensino Superior, este subsistema tem ocupado um lugar de "agente menor" do sistema educativo. Se, por um lado, a EaD se associa aos ideais de democracia, coesão social, igualdade de acesso à Educação ou da Aprendizagem ao Longo da Vida (MONTEIRO; MOREIRA; LEITE, 2016), os setores mais conservadores e grande parte das políticas que têm adotado têm sistematicamente ignorado o valor da $\mathrm{EaD}$ no quadro de mudança do Ensino Superior, traduzindo-se esta postura em silêncios ou em decisões pautadas por uma discriminação negativa.

Tratando-se de um subsistema com fortes potencialidades no campo da Educação e Formação ao Longo da Vida de nível superior, considera-se prioritária a alteração desta situação. Esta mudança deverá fazer-se acompanhar de um pensamento, de estratégia e de planos de ação de espetro amplo. São essas mudanças que analisamos neste texto, sob a forma de contributos para uma estratégia de longo prazo nacional. Esta é concebida tendo como ponto de partida a missão de serviço público da Universidade Aberta (UAb) no domínio do $\mathrm{EaD}$, isto é, tendo como premissa um alinhamento perfeito entre o futuro bem-sucedido do ensino superior a distância em Portugal e a própria raison d'être da UAb.

Não se pretende de forma alguma estudar os possíveis desenvolvimentos do EaD em Portugal, até porque esse trabalho foi já levado a cabo por um painel internacional de peritos (BIELSCHOWSKY et al., 2009). Considera-se, contudo, que o nível de abstração presente no relatório desse painel não é compaginável com a necessidade de respostas efetivas para a $\mathrm{EaD}$ no seu processo de formulação estratégica, e, nesse sentido, procura-se aprofundar e concretizar cenários possíveis de desenvolvimento disruptivos e que fabriquem Inovação. 


\section{FABRICAR A INOVAÇÃO NA ERA "PÓS-PANÓPTICA”}

Mas afinal como é que se pode produzir descoberta, invenção e, consequentemente, inovação? Segundo Isaac Newton para fabricar a inovação, criar o novo ou modificar para melhor qualquer coisa, deve-se enfrentar um percurso tenaz de investigação, pesquisa e reflexão ou verificação teórica e que, quanto mais for atento e meticuloso o estudo, mais segura é a realização do renovamento e da descoberta (D’ISRAELI, 1838). Por sua vez Dias (2016) refere que inovar é romper, desordenar e também reorganizar e construir uma nova configuração. Este é de acordo com o mesmo autor o ciclo de inovação que conduz a uma outra ordem alicerçada na periferia da representação e da qual emergem as novas linhas de ação. Inovar é, pois, a expressão do fim dos limites de uma geometria pré-concebida, estruturada e formatada, não só na dimensão do pensamento, mas também do espaço e do tempo.

Com efeito, é nesta "fluidez" e "liquidez" do tempo e dos espaços nãoestruturados que os jovens, atualmente, se movimentam e ampliam seu instinto nômade. Resultado da flexibilidade e expansividade recentemente adquiridas, o tempo é a grande arma na conquista do espaço. Na "luta" entre espaço e tempo, o espaço era o lado sólido e impassível, pesado e inerte, capaz apenas de uma guerra defensiva, de trincheiras, enquanto o tempo se afirmava como o lado dinâmico e ativo na batalha, o lado ofensivo, a força invasora, conquistadora e colonizadora. A velocidade do movimento e o acesso a meios mais rápidos de mobilidade transformaram essa realidade.

A respeito desta ideia da inovação, é interessante recuperar o pensamento de Foucault, que utilizou o projeto do Panóptico de Jeremy Bentham como arquimetáfora do poder moderno e que agora descrevemos para ilustrar esta ideia de diluição das geometrias da representação cognitiva, espacial e temporal.

No Panóptico, os reclusos estavam presos a um lugar e impedidos de qualquer movimento, confinados entre muros grossos, densos e bem-guardados. Não se podiam mover, porque estavam sob vigilância, tinham que permanecer nos lugares indicados, porque não sabiam, e nem tinham como saber, onde se posicionavam os guardas prisionais. As instalações e a facilidade de deslocação dos guardas eram a garantia da sua dominação. O domínio do tempo era o segredo do poder de quem controlava os presídios e imobilizar os reclusos no espaço, negando-lhes o direito ao movimento, era a principal estratégia no seu exercício do poder.

1

"Fluidez" é a qualidade de líquidos e gases. O que os distingue dos sólidos, como a Enciclopédia britânica refere, com a autoridade que tem, é que eles "não podem suportar uma força tangencial ou deformante quando imóveis" e assim "sofrem uma constante mudança de forma quando submetidos a tal tensão". 
No modelo de educação escolar, dessa época, a situação era similar, já que os professores não identificavam a sua atuação com a função de educar, mas sim com a função de um especialista que conhecia a fundo o conteúdo que estava a ser objeto de estudo e que, devido à autoridade que este facto lhe conferia, exercia o controlo sobre a conduta dos alunos da turma. Ou seja, o conhecimento afirmavase como um corpo sagrado, organizado para ser transmitido pela escola, através da autoridade do professor enquanto sujeito detentor do saber e responsável pela manutenção da ordem e da disciplina.

O que nos leva a falar do fim desta história de poder é que o esforço para acelerar a velocidade do movimento chegou ao seu "limite natural". Atualmente, o poder move-se com a velocidade do sinal digital e o tempo necessário para o movimento reduziu-se à instantaneidade. Ou seja, o poder tornou-se verdadeiramente extraterritorial, sendo que o advento dos dispositivos de comunicação digital, ilustram bem o "golpe de misericórdia" simbólico na dependência relativamente ao espaço. $\mathrm{Na}$ realidade, não importa mais onde está quem dá a ordem, a diferença entre "próximo" e "distante", ou entre o espaço "selvagem" e o "civilizado". O que quer que esta época seja atualmente, ela é também, e talvez acima de tudo, a era pós-Panóptica. O fim do Panóptico é o arauto do início de uma nova era digital que, no campo educacional, se afirma como móvel, pervasiva e ubíqua habitada por jovens nômades digitais.

Assim como os nômades, mal vistos na era moderna, os nômades digitais movimentam-se, mas agora no ciberespaço em busca de informação, de conhecimento, de interação, de conectividade,... que satisfaça as suas necessidades enquanto seres humanos. Os nômades digitais movimentam-se em espaços híbridos, habitando comunidades virtuais de aprendizagem, de relacionamento, de prática, blogs, chats, fóruns, mundos virtuais,... e a partir dessas interações e relações, constroem uma rede de caminhos indefinidos, presente num espaço de fluxos (CASTELLS, 2007). E nesse contexto híbrido podem assumir múltiplas representações, como avatares, personagens, imagens em $2 \mathrm{D}$ e o próprio corpo físico, movimentando-se incessante e instantaneamente, de um cenário para outro, sendo que o seu "lar" se vai configurando na rede tecida entre os diferentes espaços (LATOUR, 2005). Afirmando-se como diferente do outro na comunidade, com um lugar próprio na rede... E quando em saturação, assumindo outras formas com as suas ferramentas tecnológicas em ambientes virtuais de aprendizagem... $\mathrm{E}$ perante este quadro de rompimento, de desordem aparente, como (re) organizar e construir novos cenários de desenvolvimento para a EaD em Portugal? 


\section{CENÁRIOS DE DESENVOLVIMENTO E ESTRATÉGIAS PARA A EaD EM PORTUGAL}

Atualmente, o modelo vigente em Portugal para o ensino superior público a distância caracteriza-se por uma esmagadora liderança da UAb, acompanhado por iniciativas pontuais de algumas universidades, que criam unidades de EaD com fins muito específicos, em áreas científicas concretas. Nalguns casos, existe cooperação da UAb com essas unidades, consubstanciada na partilha de know-how e tecnologia.

\section{MODELO DE PARCERIA}

Apesar do crescimento exponencial da EaD, existem duas pressões conflituantes no quadro do seu desenvolvimento futuro. De acordo com Simonson et al. (2009), se, por um lado, a primeira escolha dos estudantes ou candidatos não é estudar a distância, por outro lado, estes indivíduos são fortemente exigentes relativamente à possibilidade de aprender a distância, no sentido em que desejam complementar a sua experiência de aprendizagem presencial com elementos do EaD. É na resposta a esta dicotomia que o modelo de parceria melhor se posiciona.

Com efeito, a tendência lógica de evolução deste modelo é no sentido da UAb se tornar parceira de todas as outras universidades, através da celebração de parcerias ou protocolos, mediante os quais a UAb disponibiliza um conjunto de valências próprias (experiência e competência em EaD, modelo pedagógico virtual, resultados do LE@ $\mathrm{D}^{2}$, etc.), enquanto as universidades parceiras retribuem com eventuais conteúdos que a UAb poderá integrar na sua oferta pedagógica.

Apesar de constituir um avanço na lógica de cooperação interinstitucional, a qual se recomenda em absoluto, com vista ao desenvolvimento da $\mathrm{EaD}$, este modelo não se afigura sustentável no longo prazo, por um conjunto de razões que de seguida se explora.

Em primeiro lugar, a oferta formativa em Portugal já se encontra significativamente pulverizada, num mercado cuja dimensão é pequena e tem tendência a diminuir, atendendo nomeadamente à pirâmide etária do nosso país. Os resultados das colocações no concurso nacional de acesso ao ensino superior público evidenciam a pulverização da oferta formativa superior num largo espectro de áreas científicas e geografias.

2 O Laboratório de Educação a Distância e eLearning $\mid$ LE@D| é uma unidade de investigação sediada na Universidade Aberta, vocacionada para a investigação e desenvolvimento em Educação a Distância e eLearning na Sociedade do Conhecimento. 
Por outro lado, o modelo de parceria dificilmente será escalável a pontos de ser rentável a nível nacional. A opção pelo estabelecimento de parcerias bilaterais implica a customização dos moldes de cada parceria à medida das entidades envolvidas. Esta abordagem tem um forte potencial de resultar em diversos submodelos possíveis, com desvantagens evidentes ao nível da capacidade de replicação em âmbito nacional. Subsidiariamente, esta opção representa um grau elevado de complexidade em termos de definição e gestão da carteira de parcerias, traduzida em esforço e, consequentemente, custos comparativamente elevados.

Adicionalmente, a longo prazo este modelo enfraquece os fatores distintivos de cada parceiro, anulando a sua identidade própria. No caso concreto da UAb, a oferta de cursos com conteúdos pedagógicos facultados por outras IES tem o potencial de se tornar banalizada caso não seja devidamente acompanhada por toda a estrutura envolvente de $\mathrm{EaD}$ (designadamente ao nível dos docentes e tutores e sobretudo do seu devido enquadramento no Modelo Pedagógico Virtual).

Por último, este modelo apresenta uma lacuna fundamental: do ponto de vista do cliente/ estudante, não existe nenhuma oferta inovadora neste tipo de abordagem ao produto -Ensino Superior. A experiência global (emocional e cognitiva) de uma aprendizagem nestas condições não é diferenciada, porquanto apenas se explora a conjugação de competências tecnológicas de $\mathrm{EaD}$ com conteúdos de ensino presencial. Por outras palavras, é um modelo em que o todo é justamente igual à soma das partes e não superior, como deveria ser para que a experiência de aprendizagem fosse efetivamente distintiva.

\section{MODELO DE COOPERAÇÃO}

Consideradas as fragilidades do modelo de parceria, bem como toda a envolvência mediata e imediata, é essencial conceber um modelo de cooperação interinstitucional no âmbito da EaD que seja capaz de contornar as questões existentes e apresentar-se robusta a longo prazo.

Torna-se claro nesse contexto que a UAb deverá surgir como uma centralidade na rede de IES, para a maioria das quais a EaD é apenas uma parte da atividade onde não possuem qualquer vantagem competitiva. Nesse modelo futuro é imperiosa a partilha de custos, que, se outra razão não houvesse, a situação do país (conjuntural e estrutural) mais do que aconselha.

O elemento central deste modelo é a criação estruturada de um espaço tecnológico, processual, metodológico e mesmo físico comum a todas as IES, exclusivamente dedicado à EaD. No modelo em causa, a UAb assume um papel de liderança na gestão e organização desse espaço, que de agora em diante se 
designará por — plataforma comum de EaD e eLearning, capitalizando a sua posição incontestável como única IES especializada em EaD em Portugal.

O modelo de prestação do serviço público é, desta forma, baseado na conjugação simultânea de duas posturas antagónicas: competição e cooperação. As IES competem entre si pela captação de estudantes ao mesmo tempo que cooperam na construção de uma plataforma extremamente avançada de utilização comum de que todos beneficiam e que não seria possível (economicamente viável) construir de forma individual. Em Portugal, este modelo tem o seu mais famoso representante na rede Multibanco, na qual participa praticamente toda a banca de retalho, sendo gerida por uma entidade especializada para o efeito, a $\mathrm{SIBS}^{3}$. De salientar que o Multibanco é hoje reconhecido internacionalmente como talvez a rede interbancária mais sofisticada do mundo, como os sucessivos prémios também atestam.

Por outro lado, a plataforma comum de EaD constitui o veículo através do qual se materializa a evolução da abordagem estratégica de disponibilização de produto para prestação de serviço. Esta transição é possibilitada pela existência de novas tecnologias, até há pouco tempo indisponíveis. O que se preconiza neste modelo é a adoção de uma plataforma tecnológica de eLearning encimada por um robusto sistema de business intelligence ${ }^{4}$, que permitirá desenvolver o processo de data mining necessário à conceção e melhoria contínua tanto da oferta pedagógica (produto) como da oferta complementar (serviço ${ }^{5}$ ). Porventura o mais reconhecido exemplo de utilização de um sistema de business intelligence como o que aqui se recomenda é o da Amazon, empresa pioneira e líder mundial na utilização deste tipo de tecnologia e metodologia.

O funcionamento da plataforma comum é consubstanciado nos vetores: Produto/Serviço, Pessoas e Processos.

3 Ao sucesso do Multibanco não terão sido alheios dois fatores: 1) o facto de a banca em 1985, ano de arranque do Multibanco, ainda não ter sido privatizada (sendo, portanto o Estado o acionista único, comum a todos os participantes) e 2) o facto de a tecnologia utilizada ser a mais avançada, beneficiando de experiências internacionais previamente encetadas. O modelo aqui apresentado para a plataforma comum de EaD comunga destes mesmos fatores.

$4 \quad$ O business intelligence é aqui entendido como o processo de recolha, transformação, carregamento e análise de grandes volumes de dados sobre atividades passadas com vista à previsão das características de atividades futuras e é largamente utilizado no mundo empresarial.

$5 \quad \mathrm{Na}$ oferta complementar poder-se-á incluir serviços como o apoio ao desenvolvimento da carreira do aluno ou ex-aluno (com apoio à preparação para entrevistas de emprego e elaboração de CVs, por exemplo) e a disponibilização de módulos de aprendizagem de soft skills tais como negociação, persuasão, liderança, assertividade, motivação, etc. 


\section{PRODUTO/ SERVIÇO}

- Conceção da oferta pedagógica e da oferta complementar de forma ajustada às necessidades dos estudantes e ex-estudantes, com base na informação de âmbito comportamental colhida ao longo do processo de aprendizagem;

- Customização integral da oferta pedagógica, dentro dos parâmetros permitidos pela A3ES, flexibilizando conteúdos pedagógicos, cargas horárias, modelos de avaliação, etc., de acordo com as preferências dos estudantes;

- Apoio proativo ao estudante baseado na compreensão do seu perfil, isto é, com base no estudo exaustivo do perfil do estudante e do seu comportamento, oferecer antecipada e sistematicamente um apoio conducente ao sucesso da experiência de aprendizagem.

\section{PESSOAS}

- Cruzamento de competências para obtenção de sinergias transversais, através da constituição de equipas mistas, oriundas de áreas científicas tradicionalmente afastadas;

- Organização das equipas em torno da cadeia de valor de criação e manutenção do produto/serviço;

- Formação de equipas comuns que constroem e mantêm a oferta pedagógica e a oferta complementar e servem a equipa nuclear de docentes e tutores;

\section{PROCESSOS}

- Panóplia de novos processos e metodologias, possibilitada pela tecnologia disponível (por exemplo: conteúdos on-demand, componente de aprendizagem aberta);

- Flexibilidade de construção modular da oferta e de dimensionamento progressivo à medida das capacidades internas e da procura;

- Marketing baseado na escalabilidade da base de dados de estudantes. 


\section{Figura 1 - Elementos do Modelo}

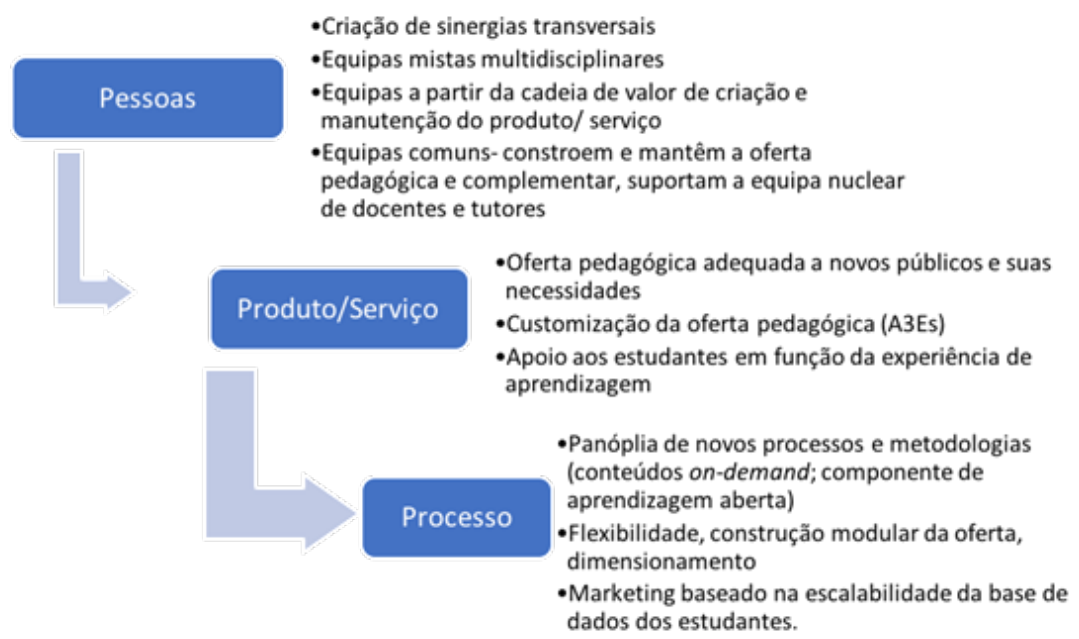

Fonte: Elaborada pelo autor.

\section{VANTAGENS DO MODELO}

Relativamente às principais vantagens associadas a este modelo destacamos as seguintes:

- Viabilidade de criação de escala a nível nacional, com todas as economias e oportunidades daí decorrentes:

- Partilha de custos e rentabilização de esforços;

- Possibilidade de focalização da oferta nas áreas de estudos que melhor servem os interesses nacionais, de forma concertada, planeada e estruturada;

- Acesso a uma base de alunos alargada (comum), cuja interação com a plataforma ajudará a alimentar os processos de melhoria contínua da própria plataforma, justificando a existência de uma equipa multidisciplinar centralizada;

- Impulso adicional na qualificação superior da população portuguesa. 
- Possibilidade de criação de um modelo de revenue ajustado ao empenho e contributo de cada membro da plataforma (por exemplo, maiores benefícios ou menores custos para os membros que representem uma maior fatia de utilizadores da plataforma comum) $)^{6}$.

- Focalização de cada player nas áreas onde apresenta vantagens competitivas, contribuindo para um modelo onde o todo é realmente superior à soma das partes, porquanto incorpora as sinergias entre as mesmas;

- Criação de uma experiência completa de aprendizagem, do ponto de vista cognitivo, emocional, social, baseada em conhecimento sólido sobre as necessidades dos alunos. A EaD afasta-se definitivamente da sua imagem de parente pobre do ensino, passando a ser percecionado como uma abordagem atrativa e procurada à transmissão de conhecimento.

\section{LIMITAÇÕES DO MODELO}

Existem também alguns riscos neste modelo, que é fundamental que sejam devidamente geridos:

- A proposta supra descrita não se esgota nos vetores propostos. Pelo contrário, carece de um maior nível de operacionalização. Por outro lado, não se pretende que seja estática (nos exatos termos em que é apresentada), antes tendo de ser perspetivada como uma proposta aberta e flexível, em resposta a um mundo que se encontra em constante mutação e que irá, inevitavelmente, requerer ajustamentos ao longo do tempo. Por essa razão, é importante acautelar a revisão periódica do modelo como um processo incorporado na própria vida do mesmo;

- Esta é uma abordagem exigente, que não será complacente com um baixo ritmo de implementação e que terá de atingir uma dimensão crítica mínima para que os resultados do processo data mining façam sentido estatístico e produzam matéria sólida para o apoio à tomada de decisões;

- O modelo só funcionará em pleno se for percorrido um caminho de acreditação, de enquadramento legislativo e de referenciais/indicadores que garantam a qualidade do ensino ali ministrado, afastando inequivocamente a ideia de que a plataforma comum possa ser uma -fábrica de diplomas. É essencial que a plataforma contribua para o alargamento e a melhoria da qualidade do ensino superior em Portugal.

6 Os detalhes específicos do funcionamento do modelo serão certamente alvo de um processo de negociação próprio entre os diversos intervenientes, não cabendo no âmbito deste estudo a sua explicitação. 


\section{NOTAS FINAIS}

Como tivemos oportunidade de referir, nos pontos anteriores, a $\mathrm{EaD}$ contribui para o desenvolvimento de novas formas de participação democrática, no quadro da globalização e incorpora, na sua matriz, o princípio de uma Educação Superior para todos e ao longo da vida, afirmando, por esta via, a sua responsabilidade social, cultural e científica.

Para além disso a EaD tem um papel central na promoção da inclusão social e digital, através de dinâmicas de rede, de parceria com organizações sociais e culturais, de âmbito global e local.

Em Portugal, a concretização destes princípios passa, entre outras, pela clarificação e regulamentação da EaD em Portugal, pela consolidação do papel da Universidade Pública de EaD neste domínio e pelo desenvolvimento de instrumentos legais em áreas específicas, como;

- Qualidade da EaD e eLearning - a urgente definição de referenciais de qualidade para a oferta educativa em EaD e eLearning;

- Financiamento da EaD - o sistema de financiamento das IES deve ser definido tendo em conta esta especificidade;

- Infraestruturas para a $\mathrm{EaD}$ - estas infraestruturas têm de acompanhar, necessariamente, a evolução tecnológica do mundo digital, exigindo, portanto, medidas de discriminação positiva também neste âmbito;

- Formação de docentes para a $\mathrm{EaD}$ - a definição de referenciais pedagógicos para o ensino e a aprendizagem em contextos digitais;

- Inovação e investigação em EaD - a criação de linhas específicas de financiamento de projetos em EaD e eLearning é uma opção fundamental para a inovação neste campo.

O que assim se evidencia é a clara consciência de uma profunda mudança conceptual e operatória do ensino a distância universitário (é ele que fundamentalmente neste texto está em causa), paralela à dinâmica de transformação das universidades convencionais, particularmente na Europa, e não raro interagindo com essa transformação. No entanto, este tipo de discurso social não se tem feito acompanhar de ações que viabilizem a sua concretização.

No caso concreto da EaD em Portugal, e das suas potencialidades na expansão do Ensino Superior, verifica-se que este subsistema não tem tido a importância devida no sistema educativo e no quadro das políticas educativas seguidas na última década. Embora fazendo parte do programa de Governo, a atual tutela do Ensino Superior praticamente ignora o ensino a distância, conforme já destacado no relatório da OCDE que referimos no início deste texto. 
Esperamos que a estratégia da inovação anunciada pelo Governo recentemente seja na verdade um passo para alterar e melhorar o cenário do ensino superior português, sobretudo com princípios e inovações operatórias fundamentais para o desenvolvimento da $\mathrm{EaD}$ em Portugal. Uma estratégia de inovação que reconheça o enorme desafio que enfrentamos, no presente, em particular, na conceção da escola para uma educação em rede digital, a qual nada tem a ver com o pensamento e a ação da escola exclusivamente direcionada para a reprodução de saberes.

Em conclusão, parece-nos que o desenvolvimento desta $\mathrm{EaD}$, em rede e digital, de proximidades e sem distância, relevante para um Portugal com futuro, depende de uma nova visão dos principais responsáveis pelo Ensino Superior em Portugal (tutela e outros stakeholders), e sobretudo da sua disposição para enveredar pelo desejável e fértil caminho da cooperação/coopetição, o único capaz de entregar uma solução estratégica nacional.

\section{REFERÊNCIAS}

BIELSCHOWSKY, C.; LAASER, W.; MASON, R.; SANGRA, A.; HASAN, A. Reforming Distance Learning Higher Education in Portugal, Ministério da Ciência, Tecnologia e Ensino Superior, 2009. Disponível em: http://www.univab.pt/pdf/news/panel_report.pdf, 6/6/2010.

CAEIRO, D.; MOREIRA, J. A. Aprendizagem ao Longo da Vida, Educação a Distância e Inclusão Digital: a criação de um campus virtual para estabelecimentos prisionais em Portugal. In: NONATO, E. R., SALES, M., MAGALHÃES DE ALBUQUERQUE, J. (Orgs.) Educação a Distância: Percursos e Perspetivas (153-186). Salvador da Bahia: Universalis, Edições UNEB- Universidade do Estado da Bahia, 2017.

CASTELLS, M. A Sociedade em Rede. A Era da Informação: Economia, Sociedade e Cultura. Lisboa: Fundação Calouste Gulbenkian, 2007.

DIAS, P. Porque temos de ser fabricantes de Inovação. In: RITA, A.; CRISTÓVÃO, F. Fabricar a Inovação. O processo criativo em questão nas Ciências, nas Letras e nas Artes. (395-396), 2016.

D'ISRAELI, Curiosities of Literature, Londres: Richard Bentley, 1838.

JENKINS, H. A Cultura da Convergência. São Paulo. Editora Aleph, 2009. 
LATOUR, B. Reassembling the social: an introduction to actor-networktheory. New York: Oxford University Press, 2005.

MONTEIRO, A.; MOREIRA, J. A.; LEITE, C. O eLearning em estabelecimentos prisionais: possibilidades e limites para a inclusão digital e justiça social. Revista Diálogo Educacional, vol. 16, n. 47, p. 77-102, 2016. Disponível em: http:// www2.pucpr.br $/ \mathrm{reol} / \mathrm{pb} /$ index.php/dialogo?dd1=16098\&dd99=view\&dd98= $\mathrm{pb}$

PORTO, C.; MOREIRA, J. A. Ambientes de Aprendizagem Digitais em Ecossistemas Educativos. In: PORTO, C.; MOREIRA, J. A. (Orgs.) Educação no ciberespaço. Novas configurações, convergências e conexões (13-20). Sergipe: Editora Universitária Tiradentes- EDUNIT, 2017.

SCHLEMMER, E. Hibridismo, Multimodalidade e Nomadismo: codeterminação e coexistência para uma Educação em contexto de ubiquidade. In: MILL, D.; REALI, A. (Eds.). Educação a Distância. Qualidade e Convergências. (6185). São Carlos: EDUFSCar, 2016.

SIMONSON, M.; SMALDINO, S. E.; ALBRIGHT, M.; ZVACEK, S. Teaching and Learning at a Distance: Foundations of Distance Education. Pearson Education: United States, 2009.

DOMINGOS CAEIRO é Professor Auxiliar do Departamento de Ciências Sociais e de Gestão (DCSG) da Universidade Aberta e Vice-Reitor desde 2010. Doutorado em Ciências Sociais e Humanas/História Contemporânea e mestre em Comunicação Educacional Multimédia e licenciado em História. Membro da Comissão Especializada de Educação do CRUP; vogal do Conselho Fiscal da AUPEC; membro do Senado e do Conselho de Gestão da UAb. Diretor do Gabinete de Gestão Académica e Curricular e coordenador da Unidade de Missão para os Centros Locais de Aprendizagem (CLA) da UAb. E-mail: domingos.Caeiro@uab.pt

JOSÉ ANTÓNIO MOREIRA é Doutor e Mestre em Ciências da Educação pela Universidade de Coimbra. Pós-Doutorado em Tecnologias Educacionais e da Comunicação pela Universidade de Coimbra. Professor Auxiliar no Departamento de Educação e Ensino a Distância da Universidade Aberta. Investigador e Coordenador do Núcleo de Estudos de Pedagogia do Ensino 
Superior (NEPES) do Centro de Estudos Interdisciplinares do Século XX (CEIS20) da Universidade de Coimbra. Atualmente é Diretor da Delegação Regional do Porto, Coordenador Executivo da Unidade de Desenvolvimento dos Centros Locais de Aprendizagem (UMCLA) e Coordenador Científico da Unidade Móvel de Investigação em Estudos do Local (ELO) da Universidade Aberta. E-mail: jmoreira@uab.pt

Recebido em março de 2018 Aprovado em abril de 2018 